Research Article

\title{
Quantitative Analysis of the Impact of Wireless Internet Technology on College Students' Innovation and Entrepreneurship under the Background of "Internet Plus"
}

\author{
Qinqin Lou (iD \\ School of Business Administration, Ningbo University of Finance \& Economics, Ningbo 315175, China \\ Correspondence should be addressed to Qinqin Lou; louqinqin@nbufe.edu.cn
}

Received 9 June 2021; Revised 27 July 2021; Accepted 3 August 2021; Published 9 August 2021

Academic Editor: Mian Ahmad Jan

Copyright ( 2021 Qinqin Lou. This is an open access article distributed under the Creative Commons Attribution License, which permits unrestricted use, distribution, and reproduction in any medium, provided the original work is properly cited.

\begin{abstract}
Under the background of "Internet plus," the opportunities and challenges that college students face in the process of innovation and entrepreneurship coexist. College students should make full use of the powerful function of the Internet to excavate the huge business opportunities hidden under the background of "Internet plus." In the context of "Internet plus" of mass entrepreneurship and innovation, the quantitative analysis method is studied in the context of wireless network technology on college students' innovation and entrepreneurship. This paper proposes a combined weight model and an evaluation model based on genetic fuzzy optimization neural network. This research initially establishes an evaluation index system (EIS) by analyzing the influence factors of wireless network technology on college students' innovation and entrepreneurship. In addition, EIS is also analyzed by combining the objective weight of each index obtained by the entropy with the subjective weight of each index obtained by the analytic hierarchy process to construct a combined weight model. A genetic algorithm is used to optimize fuzzy optimization neural networks and establish an evaluation index system of wireless network technology based on genetic fuzzy optimization neural network. To minimize the output error, the function of output error is used as the fitness evaluation function to output the score after several iterations. The experimental results show that the evaluation model can determine the importance of the influencing factors of wireless network technology on college students' innovation and entrepreneurship. It is further evident from the experiments that the proposed model has high accuracy, with the average relative error always less than $1 \%$, which can further improve the effect of quantitative analysis. The proposed model also has a fast convergence speed that can prevent local minima.
\end{abstract}

\section{Introduction}

Science and technology are the foundation of a strong country, and innovation is the soul of national progress. The general secretary Xi Jinping pointed out clearly at the meeting of academicians of both chambers that we must firmly grasp the important historical opportunity to promote scientific and technological innovation and unswervingly follow the path of China's independent innovation. The emergence of the concept of "Internet plus" has impacted the traditional industry operation mode and become the new driving force for China's economic transformation and upgrading. As a new force in social development, the rapid development of the Internet provides a new opportunity for college students to innovate and start up businesses $[1,2]$. The Internet has built a potential platform for college students' innovation and entrepreneurship. The timeliness of Internet interaction and resource sharing can enable users to interact anytime and anywhere through the Internet so that users can save labor costs to the greatest extent and improve work efficiency under resource sharing. Using the advantages of the Internet for industrial production and logistics, we can improve the efficiency of production and transaction, solve the complex and tedious problems of logistics transactions in production activities, and drive the upgrading and transformation of the industry. It also helps to seize the prominent contradictions and difficulties in industrial production, combine the advantages of the Internet for innovation, and provide a broad platform for college students' innovation and entrepreneurship [3]. 
The "Internet plus" era provides new opportunities for college students to innovate and start a business. At the same time, it also makes students face the dilemma of innovation and entrepreneurship. College students have less experience in innovation and entrepreneurship, less occupation of social resources, difficulty in obtaining funds, and inaccurate judgment and decisiveness. In the face of the ever-changing market environment, the feasibility integrity of the innovation and entrepreneurship plan formulated by college students is low, the social resources they have are difficult to support them to face the risks of innovation and entrepreneurship and lack of risk control ability, and the business scope has great limitations $[4,5]$. The university stage is the key period for students to learn professional skills, and their proficiency in the use of professional skills is low. In the process of innovation and entrepreneurship with the help of the Internet, the understanding of various new technologies is not deep enough, which brings great difficulties to college students' innovation and entrepreneurship. Therefore, we should deeply analyze the factors that influence the innovation and entrepreneurship of college students under the background of "Internet plus" and the importance of each influencing factor, to take effective strategies to cultivate and improve the innovative and entrepreneurial ability of college students.

Compared with developed countries, the research on innovation and entrepreneurship in China started late. In 1998, Tsinghua University held the first innovation and entrepreneurship competition; in 2002, the Ministry of Education listed Tsinghua University, Renmin University of China, Beijing University of Aeronautics and Astronautics, and other institutions as the pilot institutions of innovation and entrepreneurship education, which means that the innovation and entrepreneurship education in colleges and universities was officially launched in China. In 2015, the State Council put forward the general goal of innovation and entrepreneurship education which is to cultivate the innovative spirit and creativity of college students. To strengthen the implementation of innovation and entrepreneurship education reform, the Ministry of Education pointed out that, since 2016, all colleges and universities should set up innovation and entrepreneurship education courses, which should be included in the credit management. At the same time, many experts and scholars have investigated and studied the current situation and development of college students' innovation and entrepreneurship and achieved many research results. For example, Tu Jiliang used time series multiple regression analysis as the main means and used the ordered Probit model to interpret the index factors that may affect the innovation and entrepreneurship of college students under the background of "Internet plus," to provide theoretical support for improving the success rate of college students' innovation and entrepreneurship [6]. Wang et al. [7] used the network analytic hierarchy process to establish an impact evaluation model of college students' innovation and entrepreneurship. According to the weight of each index, this paper put forward countermeasures and suggestions for the development of college students' innovation and entrepreneurship.
This paper studies the quantitative analysis method of the impact of wireless network technology on the innovation and entrepreneurship of college students under the background of "Internet plus." Starting from the characteristics and development status of college students, the paper constructs an evaluation system with 12 indexes, which is used as input data based on genetic fuzzy optimization neural network evaluation model and outputs the score results after several iterations to determine the importance of each evaluation index. Based on this, this paper puts forward corresponding strategies for the cultivation and improvement of college students' innovation and entrepreneurship ability to realize the common development of college students' innovation and entrepreneurship and social economy.

The combination weight model is preferred because it improves the efficacy of the working in the context of accuracy. A fuzzy neural network also known as neurofuzzy system is a particular learning system or machine, which discovers the parameters or factors of a fuzzy system by using estimation methods of neural networks. The fuzzy neural network is preferred to integrate the assets of both FL and neural networks and create them a very powerful hybrid tool. They permit the incorporation of expert information into the method and are measured integrally and more comprehensibly. Moreover, the genetic algorithm method is preferred as it is used for resolving both unconstrained and constrained optimization challenges.

The rest of this paper is organized as follows. In Section 2 , the impact of wireless Internet technology on college students was analyzed quantitatively. The proposed approach was comprehensively evaluated through experimental results in Section 3. Finally, the paper is concluded and future research directions are provided in Section 4.

\section{Quantitative Analysis of the Impact of Wireless Internet Technology on College Students' Innovation and Entrepreneurship under the Background of "Internet Plus"}

This section provides a detailed description of the proposed analysis and model. The proposed model is a combined weight model based on genetic fuzzy optimization neural network that establishes an evaluation index system (EIS) by analyzing the influence factors of wireless network technology on college students' innovation and entrepreneurship. A genetic algorithm is utilized to enhance the fuzzy optimization neural networks and finds an evaluation index system of wireless network technology based on genetic fuzzy optimization neural network. The purpose of the model is that college students should fully understand the difficulty of innovation and entrepreneurship, actively participate in practical activities, conscientiously consolidate their professional skills, and rationally plan their goals and objectives, so as to establish a correct sense of innovation and entrepreneurship and strive to contribute to the development of social economy. 
2.1. Influencing Factors of Wireless Network Technology on College Students' Innovation and Entrepreneurship. In the era of "Internet plus," the use of the advantages of the Internet to innovate and start a business has become a new driving force for China's economic transformation and upgrading. As a new force for social development, under the social background of mass innovation and entrepreneurship, college students have a growing awareness of using Internet platforms to innovate and start businesses, and many college students have been in the Internet platform through wireless network technology for entrepreneurship, to achieve their value. Under the background of "Internet plus," the factors that influence wireless network technology on college students' innovation and entrepreneurship mainly include the following three aspects. The proposed solution can be automated as well as manual. It depends on the requirements of the application.

\subsubsection{Awareness of Innovation and Entrepreneurship.} Thinking consciousness is a necessary auxiliary condition in the process of innovation and entrepreneurship. To evaluate the maturity of thinking consciousness of innovation and entrepreneurship talents, we should judge whether they have the following spiritual consciousness:

(1) Adventurous spirit: It is an important part of innovative consciousness, which means being good at finding problems daring to question and breaking the rules.

(2) Divergent thinking: It is manifested in the wide field of thinking. Many psychologists regard this factor as the main feature of creativity. For example, students' awareness of drawing inferences from one instance is the manifestation of divergent thinking.

(3) Sense of responsibility: It is a kind of self-consciousness, the essence of which is to take the initiative to complete the task with hands and brains, which is shown as a serious attitude towards work.

(4) Service consciousness: After the start of innovation and entrepreneurship, entrepreneurs need to have service consciousness, that is, to work for the collective (or other people's) interests or a certain cause.

2.1.2. Innovation and Entrepreneurship Knowledge Level. The higher the knowledge level of college students is, the greater the creativity is and the greater the possibility of entrepreneurial success is. Rich knowledge is the basis of effective practice. The knowledge level is a quantifiable standard in the influencing factors of innovation and entrepreneurship. The following four aspects can be quantitatively analyzed through the test paper.

(1) Professional knowledge: It refers to the mastery of the professional knowledge involved.

(2) Comprehensive knowledge: The acquisition of knowledge is not limited to books, but also through a broader way to improve their knowledge level.
(3) Autonomous learning: In autonomous learning, students are the main body of learning, and it is manifested in the ability of students to collect and process information and analyze and solve problems, as well as the ability to communicate and cooperate.

(4) Cognitive ability: It is often used to test the actual learning ability and working ability of college students, including the investigation of attention and memory. It is a factor that can be quantified through the test paper.

2.1.3. Innovation and Entrepreneurship Practice. Practice is an effective way to test knowledge and ability, and an individual also can solve practical problems. The higher the practical ability is, the richer the practical experience is and the greater the possibility of entrepreneurial success is. When college students carry out innovation and entrepreneurship, most of them end up in failure. The main reason is the lack of practical ability of college students themselves $[8,9]$, which is mainly manifested in the following four aspects:

(1) Communication ability: It is a person's survival and development of the necessary ability, including listening ability, expression ability, and speculative ability.

(2) Physical fitness: The body is the capital of entrepreneurship, without a healthy physique, abundant physical strength, and energy; it is easy to affect the normal play of innovation and entrepreneurship ability.

(3) Decision-making ability: It refers to the ability to decisively and correctly choose effective methods in the face of problems and opportunities, including the investigation of college students' information extraction ability, prediction ability, and judgment ability.

(4) Practical experience: It refers to the knowledge or skills acquired from many times of practice, and it refers to the personal experience of the final results of practice, including the entrepreneurial practice results of college students and the results of competition activities.

2.2. Evaluation Index System (EIS). The EIS for analyzing the impact of wireless network technology on college students' innovation and entrepreneurship is described in this section. Constructing the evaluation index system of the impact of wireless network technology on college students' innovation and entrepreneurship should follow the principles of scientificity, comprehensiveness, dynamism, and operability [10]. The influencing factors in Section 2.1 are taken as the evaluation index of the system, and the specific evaluation index system is shown in Table 1.

The EIS is categorized into three different layers that are Target Layer, First Level Indexes, and Secondary Indexes. The Target Layer is actually the proposed EIS. The initial level indexes (First Level Indexes) include Awareness of Innovation 
TABLE 1: Evaluation index system (EIS).

\begin{tabular}{|c|c|c|}
\hline Target Layer & First Level Indexes & Secondary Indexes \\
\hline $\begin{array}{l}\text { Evaluation index system of the impact of } \\
\text { wireless network technology on college } \\
\text { students' innovation and entrepreneurship }\end{array}$ & Knowledge level of innovation and entrepreneurship & $\begin{array}{c}\text { Spirit of adventure } \\
\text { Divergent thinking } \\
\text { Sense of responsibility } \\
\text { Service consciousness } \\
\text { Professional knowledge } \\
\text { Comprehensive knowledge } \\
\text { Autonomous learning } \\
\text { Cognitive ability } \\
\text { Communication skills } \\
\text { Physical quality } \\
\text { Decision-making ability } \\
\text { Practical experience }\end{array}$ \\
\hline
\end{tabular}

and Entrepreneurship, Knowledge Level of Innovation and Entrepreneurship, and Innovation and Entrepreneurship Practice. They are further elaborated and detailed into Secondary Indexes. The Secondary Indexes are the lowest level.

2.3. Construction of Combination Weight Model. The combination weight model is preferred because it improves the efficacy of the working in the context of accuracy. The weight of each index is determined by the combination method of entropy weight model and entropy weight model. The specific steps of the method to determine the weight value of each index in the evaluation model of the impact of wireless network technology on college students' innovation and entrepreneurship are described in Figure 1. Based on the data obtained from the survey, the entropy method is used to obtain the entropy weight of each index in the evaluation index system of the impact of wireless network technology on college students' innovation and entrepreneurship. According to personal experience and background knowledge, the experts judge the importance of each index to different schemes and calculate the subjective weight. The objective weight obtained by the entropy method and the weight of experts' subjective judgment are applied to the combined weight in the best proportion [11-13].

(1) The evaluation vector matrix is established. The size of the evaluation vector matrix is kept generic $(m * n)$ that is based on the requirements. The evaluation vector matrix can be expressed as a matrix of $m * n$, where $m$ is the number of evaluation indexes and $n$ is the number of schemes. The matrix is shown in equation (1):

$$
X=\left[\begin{array}{cccc}
x_{11} & x_{12} & \ldots & x_{1 n} \\
x_{21} & x_{22} & \ldots & x_{2 n} \\
\ldots & \ldots & \ldots & \\
x_{m 1} & x_{m 2} & \ldots & x_{m n}
\end{array}\right],
$$

where $x_{i j}$ is the index value of the $i$-th index in the $j$-th scheme; $i=1,2, \ldots, m ; j=1,2, \ldots, n$.

(2) Index normalization is represented as equation (2). The index with the bigger the better is as follows:

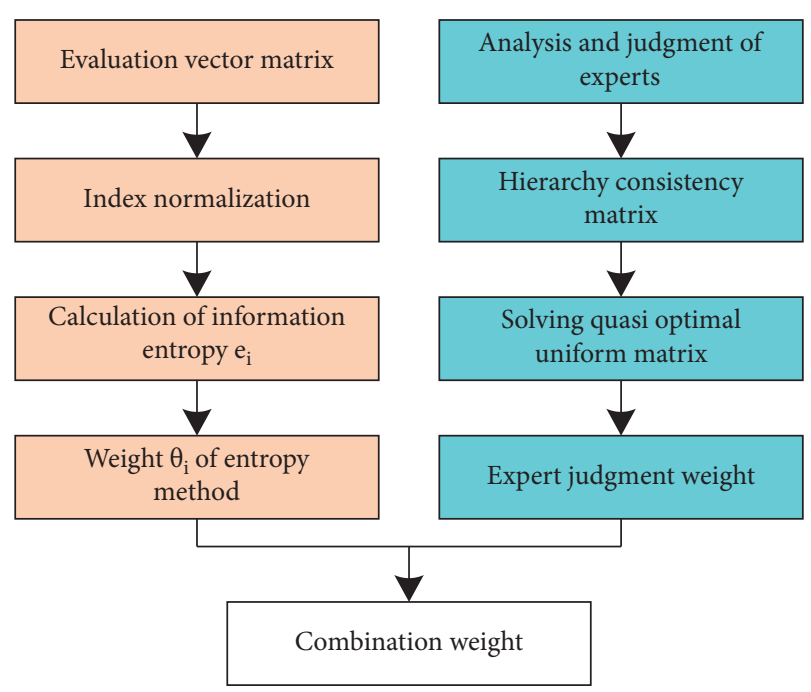

Figure 1: Construction steps of combined weight model.

$$
y_{i j}=\frac{x_{i j}-\min \left(x_{i}\right)}{\max \left(x_{i}\right)-\min \left(x_{i}\right)} .
$$

Equation (3) represents the indexes with the smaller values:

$$
y_{i j}=\frac{\max \left(x_{i}\right)-x_{i j}}{\max \left(x_{i}\right)-\min \left(x_{i}\right)} .
$$

The middle excellent index is expressed as equation (4):

$$
y_{i j}=1-\frac{\left|\bar{x}_{i}-x_{i j}\right|}{\max _{i=1, \ldots, m}\left|\bar{x}_{i}-x_{i j}\right|},
$$

where $y_{i j}$ is the evaluation coefficient of the $i$-th index in the $j$-th scheme; $x_{i j}$ is the investigation index value; $\max \left(x_{i}\right)$ and $\min \left(x_{i}\right)$ are the upper and lower limit values of each index; the middle value is generally the best weight value of each index [14].

(3) The weight is determined by the entropy method. The data of the evaluation index system are 
standardized, the standardized matrix $Y=\left\{y_{i j}\right\}_{m \times n}$ is obtained, and the proportion $p_{i j}=\left(y_{i j} / \sum_{j=1}^{n} y_{i j}\right)$ of the index value of the $j$-th region under the $i$-th index is calculated.

The information entropy of index $i$ can be defined as

$$
e_{j}=-C \sum_{i=1}^{n} p_{i j} \ln p_{i j}
$$

where $C=(\ln n)-1$ and the weight of index $j$ is $\theta_{j}=\left(1-e_{j} / \sum_{k=1}^{m}\left(1-e_{k}\right)\right)$.

(4) Subjective weight based on improved AHP: according to the influence of each index in the evaluation index system, the consistency judgment matrix $R=\left(r_{i j}\right)_{m \times m}$ is expressed as

$$
R=\left[\begin{array}{llll}
r_{11} & r_{12} & \cdots & r_{1 m} \\
r_{21} & r_{22} & \cdots & r_{2 m} \\
\cdots & \cdots & \cdots & \\
r_{m 1} & r_{m 2} & \cdots & r_{m m}
\end{array}\right]
$$

Based on the consistency judgment matrix $R$, the antisymmetric matrix is obtained by mathematical calculation, and then the optimal transfer matrix and quasioptimal consistency matrix are obtained.

(5) Combined weight: the combined weight $W=\left(w_{1}, w_{2}, \ldots, w_{m}\right)$ of each evaluation index can be calculated as equation (7):

$$
w_{j}=\frac{\theta_{j} \cdot \lambda_{j}}{\sum_{k=1}^{m}\left(\theta_{k} \cdot \lambda_{k}\right)}
$$

where $0 \leq w_{j} \leq 1, \sum_{j=1}^{m} w_{j}=1, w_{j}$ is the combination weight of $j$ index, $\theta_{j}$ is the entropy weight of the $j$ index, and $\lambda_{i}$ is the weight of $j$ index calculated by AHP.

\subsection{Evaluation Model of the Impact of Wireless Network} Technology on College Students' Innovation and Entrepreneurship. The fuzzy optimization neural network based on a genetic algorithm is used to build the evaluation model of the impact of wireless network technology on college students' innovation and entrepreneurship.

2.4.1. Fuzzy Optimization Neural Network Model. A fuzzy neural network also known as neurofuzzy system is a particular learning system or machine, which discovers the parameters or factors of a fuzzy system by using estimation methods of neural networks. The topological structure of the three-layer fuzzy optimal neural network is described in Figure 2. The input layer of the network is $m$ input nodes, that is, $m$ influence factors; the hidden layer is $l$ hidden nodes, that is, $l$ subsystem; the output layer is single node output [15].
If $n$ samples are set, the input matrix of the network is found using equation (8):

$$
R^{\prime}=\left(\begin{array}{cccc}
r_{11} & r_{12} & \cdots & r_{1 n} \\
r_{21} & r_{22} & \cdots & r_{2 n} \\
\cdots & \cdots & \cdots & \\
r_{m 1} & r_{m 2} & \cdots & r_{m n}
\end{array}\right)=\left(r_{i j}\right)
$$

where $r_{i j}$ is the normalized number of influence factor $i$ of sample $j$. The input and output of node $k$ in the hidden layer are described by equations (9) and (10), respectively.

$$
\begin{aligned}
& I_{k j}=\sum_{i=1}^{m}\left[w_{i k} r_{i j}\right], \\
& u_{k j}=\frac{1}{1+\left[I_{k j}^{-1}-1\right]^{2}},
\end{aligned}
$$

where $w_{i k}$ is the connection weight of input layer node $i$ and hidden layer node $k$.

There is only one node $p$ in the output layer. The input and output of this node are described by formula (11) and formula (12), respectively:

$$
\begin{aligned}
I_{p j} & =\sum_{k=1}^{l}\left[w_{k p} u_{k j}\right], \\
u_{p j} & =\frac{1}{1+\left[I_{p j}^{-1}-1\right]^{2}},
\end{aligned}
$$

where $w_{k p}$ is the connection weight of hidden layer node $k$ and output layer node $p$.

$u_{p j}$ is the response of fuzzy optimal neural network model to $r_{i j}$. Formulas (10) and (12) are the special cases of fuzzy variable recognition model when the distance parameter is equal to 1 (Hamming distance) and the optimization criterion parameter is equal to 2 (least square criterion). Set the actual output of sample $j$ as $M\left(u_{p j}\right)$, and its energy function is described by equation (13):

$$
E_{j}=\frac{1}{2}\left[u_{p j}-M\left(u_{p j}\right)\right]^{2} .
$$

The weight value obtained by the combined weight model is used to adjust the connection weight in the network to minimize $E[16,17]$. The formula of the connection weight adjustment between the hidden layer node $k$ and the node $p$ is as equation (14):

$$
\Delta w_{k p}=2 \eta u_{k j}^{2} u_{k j}\left[\frac{1-\sum_{k=1}^{l} w_{k p} u_{k j}}{\left(\sum_{k=1}^{l} w_{k p} u_{k j}\right)^{3}}\right]\left[M\left(u_{p j}\right)-u_{p j}\right] \text {, }
$$

where $\eta$ is learning efficiency. The formula of connection weight adjustment between input layer node $i$ and hidden layer node $k$ is as follows: 


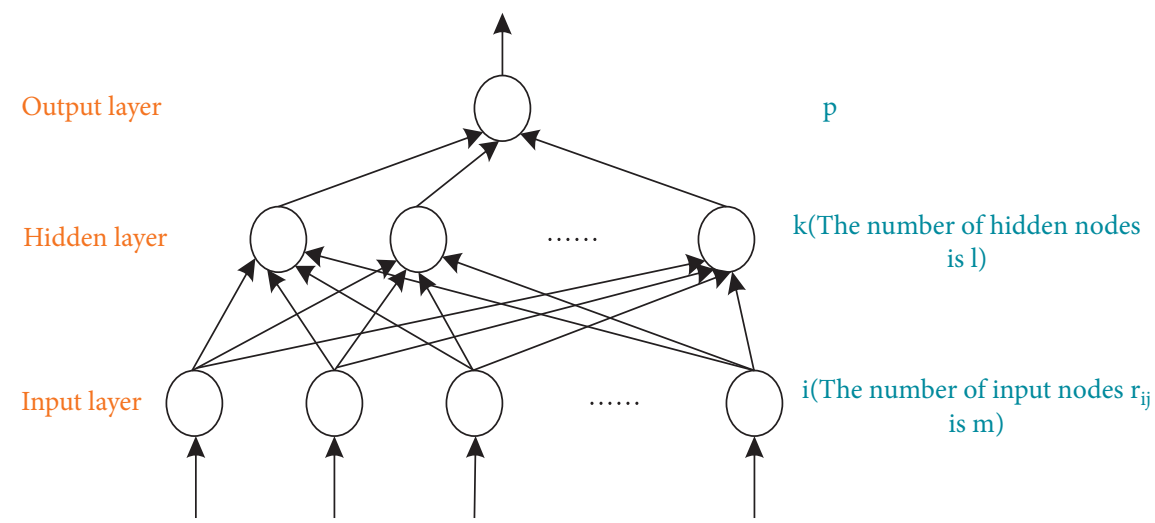

FIGURE 2: Topology of three-layer fuzzy optimal neural network.

$$
\begin{aligned}
\Delta w_{i k} & =2 \eta r_{i j} w_{k p} u_{k j}^{2}\left[\frac{1-\sum_{i=1}^{m} w_{i k} r_{i j}}{\left(\sum_{i=1}^{m} w_{i k} r_{i j}\right)^{3}}\right] \delta_{p j}, \\
\delta_{p j} & =2 u_{p j}^{2}\left[\frac{1-\sum_{k=1}^{l} w_{k p} u_{k j}}{\left(\sum_{k=1}^{l} w_{k p} u_{k j}\right)^{3}}\right]\left[M\left(u_{p j}\right)-u_{p j}\right] .
\end{aligned}
$$

Through the above model, the connection weight value of the network can be determined to minimize the error between the actual output and the expected output.

\subsubsection{Fuzzy Optimization Neural Network Model Based on} Genetic Algorithm. Aiming at the shortcomings of local minimum and slow convergence speed of neural network model, a genetic algorithm with global search characteristics is integrated into fuzzy optimization neural network algorithm $[18,19]$.

\section{(1) Determination of the coding method}

Floating-point coding has the advantages of large representation range, high precision, large search space, and easy to mix with other methods; because of the accuracy, efficiency, and convenience of calculation, floating-point coding is used in modeling, which also determines the decoding method of the problem.

(2) Initialization of population

On the premise of ensuring the sensitivity of the neural network (i.e., the net input of each node is near zero), to produce as many feasible solutions as possible when the genetic algorithm optimizes the fuzzy optimal neural network weights, the range of the initial population weights is $[-2,2]$.

(3) Calculation of fitness

The fitness of the genetic algorithm represents the excellent degree of the individual chromosome. The higher the fitness, the better the performance of the chromosome. However, the performance of the network with good initial weights and thresholds is not necessarily good. Only the output error of the neural network after training the initial weights and thresholds for a certain number of times can reflect the excellent performance of the initial weights and thresholds. The training times should not be too many; otherwise, it will lose the significance of using the genetic algorithm to optimize the neural network; when the neural network is trained, the output error of the network changes most obviously in the first dozens of times [20]. The model uses the following function of the output error $E$ of the fuzzy optimal neural network after 25 times of training as the fitness evaluation function, where $E$ is the average relative error between the actual output of the network and the expert score.

$$
f(E)=\frac{1}{(1+10 \times E)} .
$$

(4) Determination of other parameters of genetic algorithm

The model population size is set to 35 and the termination condition is as follows:

$$
E \leq \varepsilon_{1} \text {. }
$$

Moreover, the maximum number of iterations is 15 , the roulette is used for selection operation, the uniform arithmetic crossover is used for crossover operation, the probability is 0.6 , the uniform mutation is used for mutation operation, and the probability is 0.05 .

(5) Determination of neural network parameters

In the modeling process, empirical rules are designed according to the network structure: "thumb rule" which is "pyramid rule" (the number of nodes from input layer to output layer is decreasing).

$$
\begin{aligned}
m & =\frac{n+l}{2} \\
\text { or } m & =\sqrt{\frac{n+l}{2}} .
\end{aligned}
$$

Similarly, the hidden layer neuron estimation formula of trial algorithm is as follows: 


$$
m=\sqrt{n \times l} .
$$

The 5-3-1 model structure with better effect is selected through repeated trial and calculation. The end condition of neural network training is $E \leq \varepsilon_{2}$ or the maximum training time is reached (fine-tuning 2000 times for the approximate optimal value searched by genetic algorithm).

2.4.3. Process of Evaluation Model. In this paper, the Delphi program is used to realize the evaluation model, and the specific process is described in Figure 3.

(1) Determine the coding method, termination conditions, and other parameters of genetic algorithm, and initialize the population.

(2) Decode the solution space, use the fuzzy optimization neural network to train the output error $E 25$ times, and calculate the individual chromosome fitness using the given formula

$$
f(E)=\frac{1}{(1+10 \times E)} .
$$

(3) Judge whether the termination condition of genetic algorithm is reached $\left(E \leq \varepsilon_{1}\right)$ or the maximum number of iterations is 15 . If the termination condition is reached, go to step (5); otherwise perform the following steps.

(4) Carry out genetic operation (selection operation, crossover operation, and mutation operation) to generate a new generation of chromosomes, and go to step (2).

(5) Use the neural network to fine-tune the approximate optimal value searched by the genetic algorithm to improve the accuracy of the solution until the neural network fine-tuning termination condition $\left(E \leq \varepsilon_{2}\right)$ or the maximum number of training 2000 is reached and the output result is obtained. Flow of the evaluation model is shown in Figure 3.

\section{Experimental Results}

This section provides comprehensive validation of the proposed study. The proposed model is experimentally tested and verified using authentic data. This study takes 500 senior students of computer major in a university as an experiment object and uses the proposed method to quantify the impact of wireless Internet technology on college students' innovation and entrepreneurship under the background of Internet plus. A questionnaire survey is conducted among 500 students, including 300 boys and 200 girls. Starting from the characteristics and development status of the respondents, the evaluation index in Table 1 is set as the questionnaire survey option to understand the importance of wireless network technology on college students' innovation and entrepreneurship. The results are described in Table 2. Table 2 describes the survey results including the influence factors along with the numbers of girls and boys. The evaluation factors are elaborated in Table 1, which describes the EIS. The EIS is classified into 3 layers. The First Level Indexes include Awareness of Innovation and Entrepreneurship, Knowledge Level of Innovation and Entrepreneurship, and Innovation and Entrepreneurship Practice. They are further elaborated and detailed into Secondary Indexes. The Secondary Indexes are the lowest level.

Table 3 describes the weights utilized in the proposed system. The entropy weight, subjective weight, and combination weight of each index are taken into consideration. The weights are obtained using the entropy and subjective methods in the EIS.

In the evaluation index system of the impact of wireless network technology on college students' innovation and entrepreneurship, each index is used as the input of the evaluation model, and the expert score is used as the output of the evaluation model. For the input data of the evaluation model, the Sigmoid distribution transformation is used to implement the normalization processing, because the Sigmoid distribution transformation has the function of data compression, which can not only reduce the abnormity of some abnormal data and reduce the influence of the abnormity of the abnormal data on the modeling but also retain the role of the abnormal data in the modeling, making the results more scientific and reliable.

The equation of Sigmoid distribution transformation is as follows:

$$
y_{i}=\frac{1}{1+b e^{-a x_{i}}},
$$

where $x_{i}$ is the original evaluation index value, $y_{i}$ is the evaluation index value after conversion, and $a$ and $b$ are the parameters to be determined. The value range of the expert score of the output results of the evaluation model is $[0,5]$, which is directly transformed into $[0,1]$ by linear scaling transformation: $y_{i}=x_{i} / 5$. Repeat the test 5 times, and the scoring results of each index in the evaluation index system are described in Table 4.

Table 4 describes that the score of every index is proportional to the weight of the respective index that is elaborated in Table 3. The larger the weight value is, the higher the corresponding score is, and the index would be higher too. The scores of the five tests are close to the actual situation reflected in the questionnaire survey, and the evaluation results are accurate and reliable. The top three are practical experience, divergent thinking, and decisionmaking ability. Therefore, in the process of innovation and entrepreneurship, college students should pay special attention to the cultivation and promotion of these five aspects of ability. Comparing these data, it can be concluded that the evaluation model can determine the importance of wireless network technology to the factors affecting the innovation and entrepreneurship of university students and can achieve a quantitative analysis of the impact of wireless Internet technology on college students' innovation and entrepreneurship under the background of "Internet plus," and the analysis results are of high accuracy and reliability. 


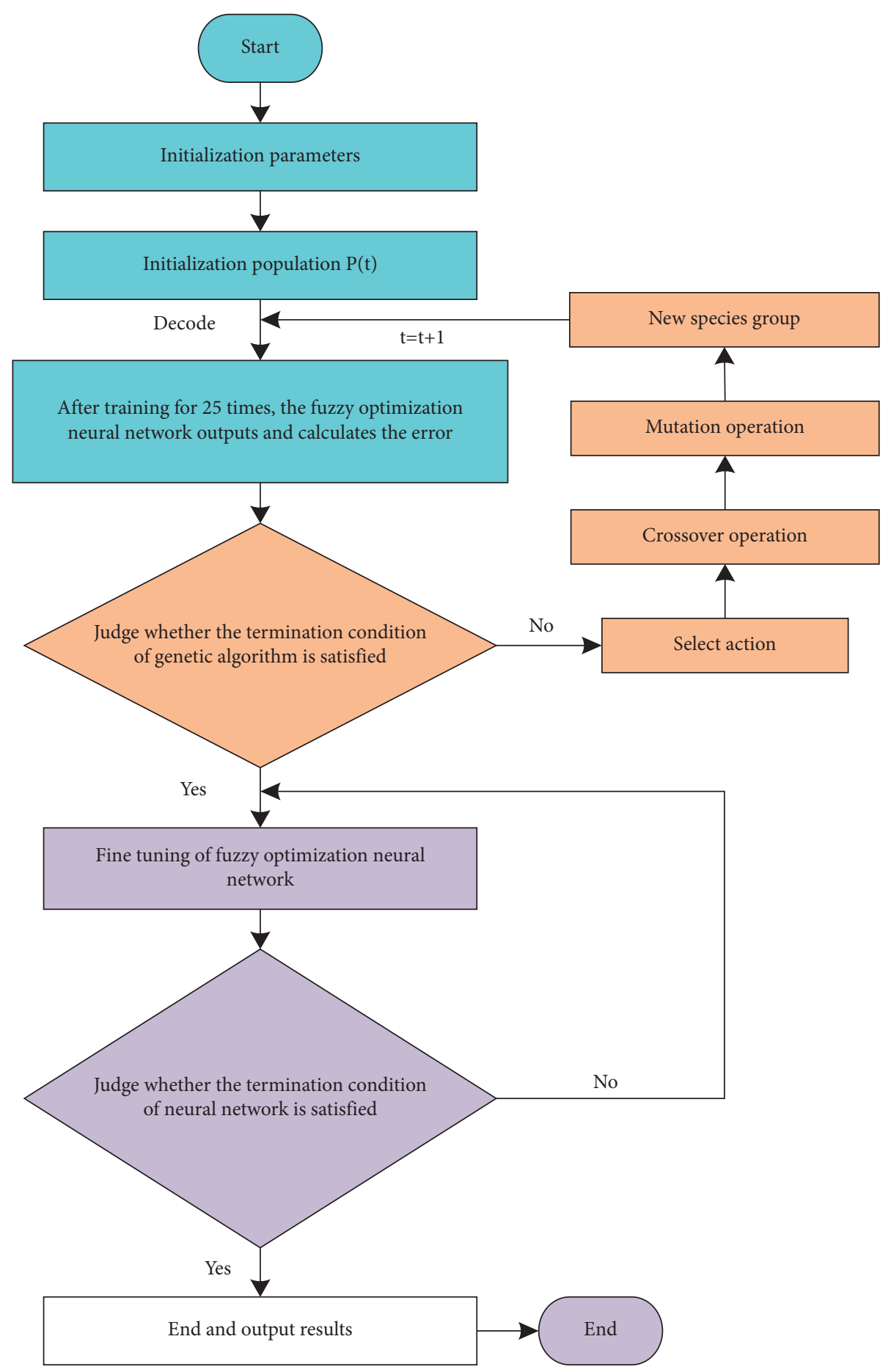

Figure 3: Flow of evaluation model.

To further analyze the performance of the proposed method, the average convergence time of the fuzzy optimal neural networks before and after improvement under different iterations is analyzed experimentally. The results are shown in Figure 4. It can be seen from the analysis of Figure 4 that the average convergence time of the improved fuzzy optimization neural network is extremely stable, always less than $0.4 \mathrm{~s}$; when the number of iterations is less than 40 , the average convergence time of the improved fuzzy optimization neural network is relatively low; when the number of iterations is more than 40 , the average convergence time rises rapidly and then gradually tends to be stable; when the number of iterations increases to 160 , the average convergence time increased to about $1.1 \mathrm{~s}$. Comparing these data, it can be concluded that the improved fuzzy optimization neural network based on a genetic algorithm has a faster convergence speed. Integrating a genetic algorithm into fuzzy optimization neural networks can improve the 
TABLE 2: Survey results of importance of influencing factors.

\begin{tabular}{lcc}
\hline Influence factor & Number of boys & Number of girls \\
\hline Spirit of adventure & 28 & 14 \\
Divergent thinking & 38 & 27 \\
Sense of responsibility & 12 & 10 \\
Service consciousness & 18 & 11 \\
Professional knowledge & 33 & 22 \\
Comprehensive knowledge & 32 & 20 \\
Autonomous learning & 29 & 16 \\
Cognitive ability & 10 & 9 \\
Communication skills & 20 & 13 \\
Physical quality & 5 & 6 \\
Decision-making ability & 35 & 23 \\
Practical experience & 40 & 29 \\
Spirit of adventure & 28 & 14 \\
\hline
\end{tabular}

TABLE 3: Evaluation index weight results.

\begin{tabular}{lccc}
\hline Evaluating index & Entropy weight & Subjective weight & Combination weight \\
\hline Spirit of adventure & 0.0456 & 0.0351 & 0.0102 \\
Divergent thinking & 0.2746 & 0.2208 & 0.3890 \\
Sense of responsibility & 0.0151 & 0.0364 & 0.0034 \\
Service consciousness & 0.0325 & 0.0375 & 0.0077 \\
Professional knowledge & 0.0645 & 0.0392 & 0.0162 \\
Comprehensive knowledge & 0.0585 & 0.0324 & 0.0120 \\
Autonomous learning & 0.0584 & 0.0312 & 0.0116 \\
Cognitive ability & 0.0151 & 0.0330 & 0.0031 \\
Communication skills & 0.0456 & 0.0309 & 0.0089 \\
Physical quality & 0.0090 & 0.0330 & 0.0018 \\
Decision-making ability & 0.0888 & 0.1794 & 0.1022 \\
Practical experience & 0.2325 & 0.2898 & 0.4323 \\
\hline
\end{tabular}

TABLE 4: Scoring results of evaluation indexes.

\begin{tabular}{lccccc}
\hline Evaluating index & 1 & 2 & 3 & 4 & 5 \\
\hline Spirit of adventure & 0.59 & 0.58 & 0.59 & 0.57 & 0.57 \\
Divergent thinking & 0.8 & 0.81 & 0.83 & 0.81 & 0.82 \\
Sense of responsibility & 0.46 & 0.45 & 0.45 & 0.47 & 0.46 \\
Service consciousness & 0.5 & 0.49 & 0.51 & 0.51 & 0.52 \\
Professional knowledge & 0.69 & 0.70 & 0.68 & 0.71 & 0.69 \\
Comprehensive knowledge & 0.65 & 0.66 & 0.65 & 0.64 & 0.66 \\
Autonomous learning & 0.61 & 0.62 & 0.60 & 0.61 & 0.62 \\
Cognitive ability & 0.42 & 0.41 & 0.42 & 0.43 & 0.41 \\
Communication skills & 0.55 & 0.54 & 0.55 & 0.56 & 0.55 \\
Physical quality & 0.31 & 0.32 & 0.30 & 0.31 & 0.32 \\
Decision-making ability & 0.78 & 0.77 & 0.76 & 0.77 & 0.78 \\
Practical experience & 0.85 & 0.86 & 0.85 & 0.84 & 0.86 \\
\hline
\end{tabular}

convergence speed of fuzzy optimization neural networks and prevent local minimum.

The index of the evaluation is introduced into the training model of the network. The required learning efficiency is set to 0.01 and the expected error is set to 0.001 to have the improved performance. Moreover, the maximum number of training is 25 times to prove the efficiency of the repetition end condition of the assessment model. The results are depicted in Figure 5.

It can be seen from the analysis of Figure 5 that when the number of iterations reaches the 15 th, the average relative error is $0.00099<0.001$, and the iteration stops, meeting the iteration termination conditions of the evaluation model.
Therefore, it is reasonable to set the maximum number of iterations to 15 in the evaluation model. At this time, the network obtained by training is used to simulate the evaluation indexes, and the score simulation values are obtained. The 12 evaluation indexes are represented by numbers $1-12$, respectively. The comparison results between the score simulation values and the actual values are described in Figure 6.

According to the analysis of Figure 6, the changing trend of the simulated score obtained through training is completely consistent with the actual value and fluctuates slightly around the actual value, which is also in line with the actual situation of the questionnaire survey in Table 2 . Therefore, the proposed method can be used to quantify the accuracy of the Internet plus technology in the context of Internet plus.

Under different iterations, this paper quantitatively analyzes the average relative error of the impact of wireless network technology on college students' innovation and entrepreneurship and designs a comparative experiment. It selects the correlation analysis and evaluation method of innovation and entrepreneurship education resources and science and technology innovation service function of local colleges and universities in [6] and the emerging evaluation method based on network analytic hierarchy process in [7] as a comparison method of the methods in this paper; the average relative error results of quantitative analysis of the three methods are described in Figure 7. 


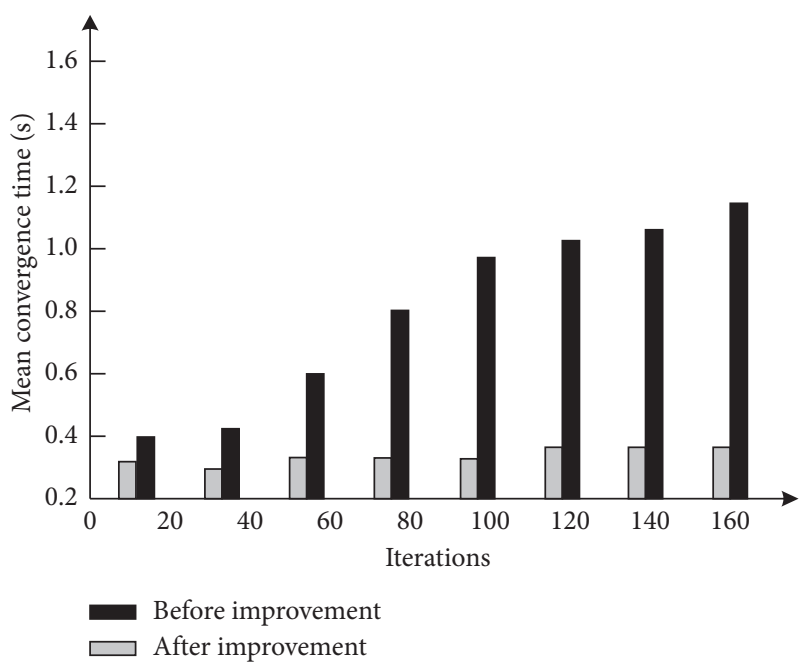

Figure 4: Comparison of average convergence time results.

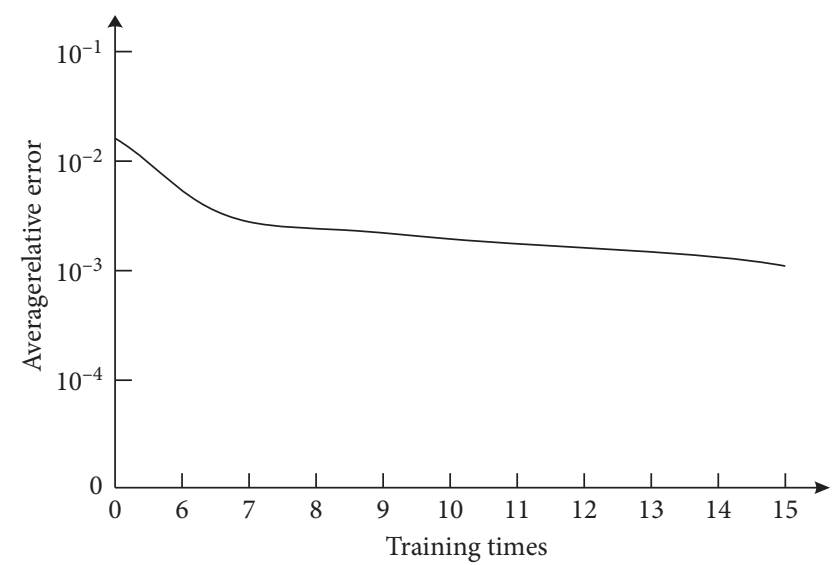

FIGURE 5: Iteration stop condition.

According to the analysis of Figure 7, compared with the other two methods, the average relative error of the proposed method always keeps the lowest changes smoothly and is controlled below $1 \%$; the average relative error of the correlation evaluation method fluctuates obviously in the range of $[1 \%, 3 \%]$; the average relative error of analytic hierarchy process evaluation method fluctuates greatly in the range of $[2 \%, 6 \%]$ and is extremely unstable. Comparing these data can show that the proposed method has a good quantitative analysis effect on the impact of wireless network technology on college students' innovation and entrepreneurship and can accurately judge the importance of each influencing factor, followed by the correlation evaluation method, the quantitative analysis effect of AHP evaluation method is the worst, and the performance needs to be improved.

The performance analysis of the proposed model is provided with other models. Only 2 other models are considered due to the domain relevance. The models are examined from four features that are population size, iteration times, network fine-tuning times, and correlation. The comparative analysis is provided in Table 5 .

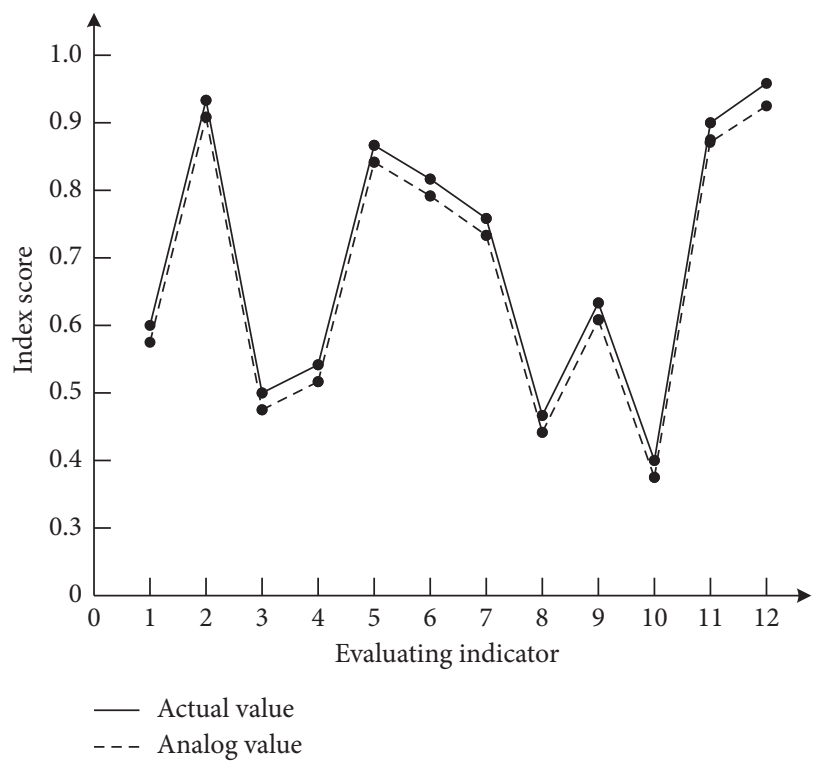

Figure 6: Comparison of simulated value and actual value.

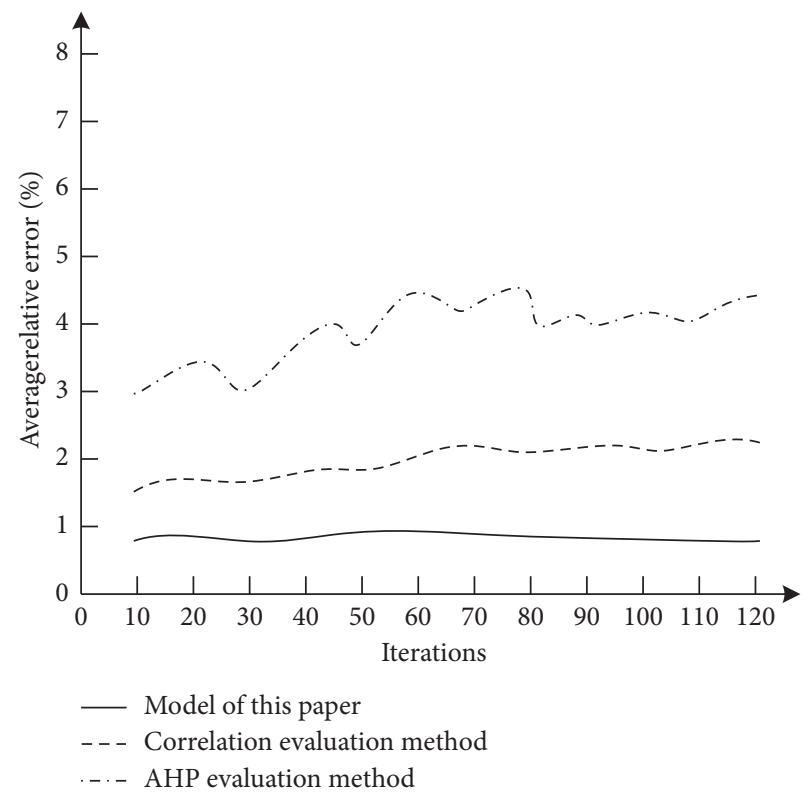

FIGURE 7: Comparison of average relative error results.

TABle 5: Performance comparison.

\begin{tabular}{lccc}
\hline $\begin{array}{l}\text { Performance } \\
\text { index }\end{array}$ & $\begin{array}{c}\text { Proposed } \\
\text { model }\end{array}$ & Correlation & AHP \\
\hline Population size & 40 & 50 & 60 \\
Iterations & 15 & 1250 & 1024 \\
Network & $<2000$ & - & - \\
fine-tuning times & times & Above & Above \\
Relevance & Above & 0.92 & 0.90 \\
\hline
\end{tabular}

According to Table 5, the population size of the correlation evaluation method and analytic hierarchy process evaluation method is 50 and 60, respectively. The correlation between model training results and expert scoring results is 
above 0.92 and 0.90 , respectively, which requires more than 1000 iterations to obtain a better solution. Compared with the other two methods, the population size of the proposed method is 40 , which only needs 15 iterations, and then, the neural network is used to fine-tune about 2000 iterations to get a better solution. Therefore, it can be explained that the overall performance of the proposed method has more advantages and can better achieve the quantitative analysis of the impact of wireless Internet technology on the innovation and entrepreneurship of college students under the background of "Internet plus."

\section{Conclusion}

This paper constructs a combined weight model and an evaluation model based on genetic fuzzy optimization neural network to realize the quantitative analysis of the impact of wireless Internet technology on college students' innovation and entrepreneurship under the background of "Internet plus." The experimental results show that the proposed method can determine the importance of each evaluation index that has a good quantitative analysis effect, and the analysis results are accurate and reliable. The evaluation model applied in this paper has a fast convergence speed that can prevent local minima, the iteration termination condition has high rationality, the ideal solution can be obtained after 15 iterations, and the overall performance advantage is significant. The proposed method has high accuracy, with the average relative error always less than $1 \%$, which can further improve the effect of quantitative analysis. The college students should fully understand the difficulty of innovation and entrepreneurship, actively participate in practical activities, conscientiously consolidate their professional skills, and rationally plan their goals and objectives, so as to establish a correct sense of innovation and entrepreneurship and strive to contribute to the development of social economy.

\section{Data Availability}

The data used to support the findings of this study are available from the author upon request.

\section{Conflicts of Interest}

The author declares that he has no conflicts of interest.

\section{References}

[1] M. Portuguez Castro, C. Ross Scheede, and M. G. Gómez Zermeño, "The impact of higher education on entrepreneurship and the innovation ecosystem: a case study in Mexico," Sustainability, vol. 11, no. 20, Article ID 5597, 2019.

[2] X. Li, C. Pak, and K. Bi, "Analysis of the development trends and innovation characteristics of internet of things technology-based on patentometrics and bibliometrics," Technology Analysis \& Strategic Management, vol. 32, no. 4, pp. 1-15, 2019.

[3] M. J. Beynon, P. Jones, and D. Pickernell, "The role of entrepreneurship, innovation, and urbanity-diversity on growth, unemployment, and income: us state-level evidence and an fsqca elucidation," Journal of Business Research, vol. 101, pp. 675-687, 2019.

[4] S. Yuan, H. J. Yu, X. H. Yang, M. Liu, and B. Tang, "The impact of a health education intervention on health behaviors and mental health among Chinese college students," Journal of American College Health, vol. 68, no. 5, pp. 1-6, 2019.

[5] S. M. Chege and D. Wang, "Information technology innovation and its impact on job creation by SMEs in developing countries: an analysis of the literature review," Technology Analysis \& Strategic Management, vol. 32, no. 3, pp. 256-271, 2020.

[6] J. L. Tu and Q. X. Tao, "Relevance analysis and evaluation model of innovation and entrepreneurship education resources and service function of science and technology innovation in local universities," Science \& Technology Progress and Policy, vol. 37, no. 8, pp. 159-166, 2020.

[7] G. H. Wang, D. Xu, and H. Huang, "Research of evaluation model of business dynamic ability in emerging industries based on ANP theory," Science and Technology Management Research, vol. 39, no. 23, pp. 75-82, 2019.

[8] N. Yasir, N. Mahmood, H. S. Mehmood, M. Babar, M. Irfan, and A. Liren, "Impact of environmental, social values and the consideration of future consequences for the development of a sustainable entrepreneurial intention," Sustainability, vol. 13, no. 5, Article ID 2648, 2021.

[9] H.-K. Lim and Y.-H. Khang, "Quantifying the impact of reducing socioeconomic inequalities in modifiable risk factors on mortality and mortality inequalities in South Korea," International Journal of Public Health, vol. 64, no. 4, pp. 585-594, 2019.

[10] N. Szumilo and E. Vanino, "Mortgage affordability and entrepreneurship: evidence from spatial discontinuity in helpto-buy equity loans," Journal of Business Venturing, vol. 36, no. 4, Article ID 106105, 2021.

[11] H. Y. Zhao, X. T. Liu, and X. L. Zhang, "Research on establishing trust evaluation mechanism of user services on cloud platform," Computer Simulation, vol. 35, no. 1, pp. 418-422, 2018.

[12] B. Orlando, L. V. Ballestra, V. Scuotto, M. Pironti, and M. D. Giudice, "The impact of R\&D investments on ecoinnovation: a cross-cultural perspective of green technology management," IEEE Transactions on Engineering Management, vol. 5, no. 99, pp. 1-10, 2020.

[13] G. H. Ionescu, D. Firoiu, R. Pîrvu, M. Enescu, M.-I. Rădoi, and T. M. Cojocaru, "The potential for innovation and entrepreneurship in eu countries in the context of sustainable development," Sustainability, vol. 12, no. 18, Article ID 7250, 2020.

[14] M. Tang, P. Xu, P. Llerena, and A. Afshar Jahanshahi, "The impact of the openness of firms' external search strategies on exploratory innovation and exploitative innovation," Sustainability, vol. 11, no. 18, Article ID 4858, 2019.

[15] B. D. Pauw and P. V. Petegem, "Eco-school evaluation beyond labels: the impact of environmental policy, didactics and nature at school on student outcomes," Environmental Education Research, vol. 24, no. 9-10, pp. 1250-1267, 2018.

[16] T. Byers, E. Hartnell-Young, and W. Imms, "Empirical evaluation of different classroom spaces on students' perceptions of the use and effectiveness of 1-to-1 technology," British Journal of Educational Technology, vol. 49, no. 1, pp. 153-164, 2018.

[17] J. Lee and M. M. Shepley, "College campuses and student walkability: assessing the impact of smartphone use on student perception and evaluation of urban campus routes," Sustainability, vol. 12, no. 23, Article ID 9986, 2020. 
[18] S. Mallavarapu and L. A. Taglialatela, "A post-occupancy evaluation of the impact of exhibit changes on conservation knowledge, attitudes, and behavior of zoo visitors," Environmental Education Research, vol. 25, no. 4, pp. 1-18, 2019.

[19] M. Koko and M. Kara, "A multiple study investigation of the evaluation framework for learning analytics: instrument validation and the impact on learner performance," Educational Technology \& Society, vol. 24, no. 1, pp. 16-28, 2021.

[20] G. Tang, K. Park, A. Agarwal, and F. Liu, "Impact of innovation culture, organization size and technological capability on the performance of smes: the case of China," Sustainability, vol. 12, no. 4, Article ID 1355, 2020. 